\title{
Development of Allometric Equations for Estimating Above-Ground Liana Biomass in Tropical Primary and Secondary Forests, Malaysia
}

\author{
Patrick Addo-Fordjour ${ }^{1,2}$ and Zakaria B. Rahmad ${ }^{1}$ \\ ${ }^{1}$ School of Biological Sciences, University of Science Malaysia, 11800 Pulau Penang, Penang, Malaysia \\ ${ }^{2}$ Department of Theoretical and Applied Biology, College of Science, Kwame Nkrumah University of Science and Technology (KNUST), \\ Kumasi, Ghana
}

Correspondence should be addressed to Patrick Addo-Fordjour; paddykay77@yahoo.com

Received 26 February 2013; Accepted 4 June 2013

Academic Editor: Shibu Jose

Copyright (C) 2013 P. Addo-Fordjour and Z. B. Rahmad. This is an open access article distributed under the Creative Commons Attribution License, which permits unrestricted use, distribution, and reproduction in any medium, provided the original work is properly cited.

\begin{abstract}
The study developed allometric equations for estimating liana stem and total above-ground biomass in primary and secondary forests in the Penang National Park, Penang, Malaysia. Using biomass-diameter-length data of 60 liana individuals representing 15 species, allometric equations were developed for liana stem biomass and total above-ground biomass (TAGB). Three types of allometric equations were developed: models fitted to untransformed, weighted, and log-transformed $\left(\log _{10}\right)$ data. There was a significant linear relationship between biomass and the predictors (diameter, length, and/or their combinations). The same set of models was developed for primary and secondary forests due to absence of differences in regression line slopes of the forests (ANCOVA: $P>0.05$ ). The coefficients of determination values of the models were high (stem: 0.861 to 0.990; TAGB: 0.900 to 0.992). Generally, log-transformed models showed better fit (Furnival's index, FI $<0.50$ ) than the other models $(\mathrm{FI}>0.5)$. A comparison of the best TAGB model in this study (based on FI) with previously published equations indicated that most of the equations significantly $(P<0.05)$ overestimated TAGB of lianas. However, a previous equation from Southeast Asia estimated TAGB similar to that of the current equation $(P>0.05)$. Therefore, regional or intracontinental equations should be preferred to intercontinental equations when estimating liana biomass.
\end{abstract}

\section{Introduction}

Lianas have great influence on forest ecosystems, especially in tropical forests [1]. They contribute very much to species diversity in the tropics, constituting as high as $38 \%$ of species diversity [2]. They may compose of a much higher percentage (45\%) with regard to total woody plant stems in the tropics (cf. [3]). Lianas serve as an important source of food for forest fauna especially in the dry season [4]. They may provide up to about one-third of canopy foliage in the forest (cf. [5]) and therefore contribute substantially (up to 36\%) to total above-ground leaf biomass in tropical forest ecosystems [6]. Lianas compete with trees which may affect tree growth $[7,8]$. Additionally, they may have negative influence on seed production of trees and also impede natural regeneration of trees [7-9].

Tropical forest ecosystems continue to be exploited at alarming rates resulting in their conversion to secondary forests and many other forms of land use [10]. A high proportion of forests in the tropics is made up of secondary forests [11]. In Malaysia, many lowland dipterocarp forests have been converted to secondary forests as a result of logging, farming, and other human activities (cf. [12]). With changes in tropical forest ecosystems as a result of human disturbance, the ability of secondary forests to accumulate biomass may be altered. Even within primary forests, changes in biomass stock may occur from time to time due to other factors which elicit changes in forest composition, 
structure, diversity, and productivity $[13,14]$. Consequently, there is the need to assess biomass levels of primary and secondary forests from time to time. Knowledge of the amount of biomass stored up within forests is important for a couple of reasons. Firstly, biomass data is fundamental in evaluating the productivity, structure, and conditions of forests [15]. Secondly, biomass measurements are useful in estimating the amount of carbon sequestered by forests [16]. Furthermore, it plays an important role in elucidating the effects of deforestation and carbon sequestration on global carbon balance [16]. Although lianas continue to increase in biomass in tropical forests [17], they have not been factored in most forest biomass assessments. In recent times, there have been growing calls for more biomass assessment of tropical forests because of the need to estimate forest carbon stocks and the potential amount of biomass available as a source of energy [18]. Unfortunately, all the calls were made in relation to only tree biomass with no mention of lianas. This is quite unfortunate in view of the fact that lianas can add up to $30 \%$ of total above-ground biomass in tropical forests with dense liana population (cf. [17]).

Though there are several ways of determining biomass of plants in forests [18], two main approaches are commonly used. These are destructive harvesting of plants and then determining their biomass, and the use of allometric equations to predict biomass of plants. However, it is preferable that allometric equations be used to estimate forest biomass as they allow for the estimation of large forest areas and avoid destruction of forest. There are many allometric equations that have been developed for the estimation of plant biomass in many tropical forests. Nevertheless, most of the allometric equations are for trees, with only a few on lianas. The scarcity of liana allometric equations is partly due to the difficulty in accessing the whole length of lianas from trees. Currently, it is known that lianas can contribute up to $30 \%$ of total aboveground biomass in liana-dense tropical forests (cf. [17]). Since lianas are disturbance adapted group of plants [19], they are likely to increase in abundance in the face of increasing disturbance in tropical forests, and therefore their biomass could even be higher. With this development, the importance of lianas in the forest would continue to increase with time, and, therefore, ignoring them in biomass assessment of forests could lead to underestimation of forest biomass [20]. Accordingly, lianas should be integrated into tropical forest biomass assessments so as to obtain the true amount of tropical forest biomass. To this end, more allometric equations of lianas must be developed for tropical forest ecosystems to make biomass determination of lianas possible, and an integral part of forest biomass assessment.

Even though a few liana allometric equations have been developed for the estimation of above-ground biomass in tropical forests $[3,20,21]$, there is no allometric equation for lianas in Malaysia. To date, only one allometric equation has been developed for the estimation of liana biomass in the whole of Southeast Asia [22]. To know the relative contribution of above-ground plant parts to total aboveground biomass, plant part allometric equations must be developed. Most liana allometric equations in use only measure total above-ground biomass without the individual

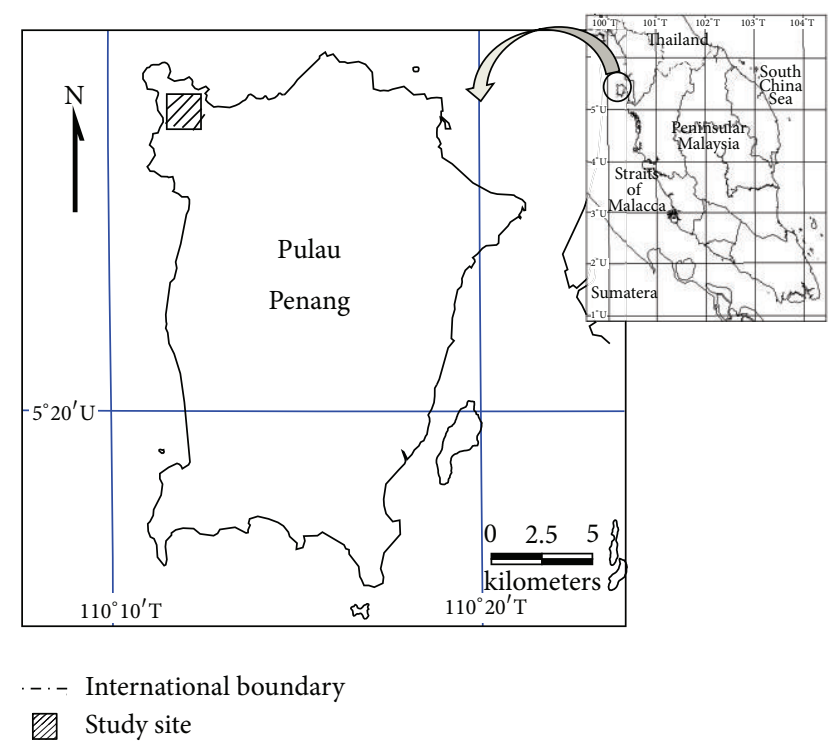

FIGURE 1: Map of Penang State showing the location of the study area (Penang National Park).

components. Since above-ground portion of lianas have two main components (stem and leaf), developing allometric equations for at least one of them should make it possible to determine the biomass of the other component, when it is used in conjunction with total above-ground biomass equations. Therefore, the study was aimed at developing allometric equations for the estimation of stem and total above-ground biomass of lianas in primary and secondary forests within the Penang National Park, Penang, Malaysia.

\section{Materials and Methods}

2.1. Study Area. The study was conducted in the Penang National Park, Penang, Malaysia (N $5^{\circ} 27.583^{\prime}$ E $100^{\circ} 12.350^{\prime}$ ) (Figure 1), which has a total area of 1,213 ha. The national park is comprised of primary and secondary forest types. The park contains many plant species (1000 species), the majority of which are from Dipterocarpaceae, Fabaceae, Apocynaceae, Anacardiaceae, Euphorbiaceae, and Moraceae. A total of 190 species of animals have been recorded, and these include 25 mammal species, 53 butterfly species, 46 bird species, and other reptiles, insects, and amphibians [23]. The Penang National Park was designated as a national park in April 4, 2003, and gazetted under National Park Act 226 of 1980 on April 10, 2003.

The secondary forest within the Penang National Park has experienced various forms of human disturbance since the early years of the twentieth century. Logging was a major form of disturbance in the secondary forest although human activities such as farming, hunting, and gathering occurred in it. The secondary forest possesses relics of considerable historical land use activities such as clearcutting, farming, logging, and bush burning, due to its close proximity to the community. The secondary forest is also characterised by some ancient logging routes, confirming its extensive use 
in the distant past. The provision of infrastructure in the secondary forest of the national park has also contributed to loss of forest cover and resulted in fragmentation in some parts of the forest. Human disturbance has significantly influenced liana diversity and structure in the secondary forest [24].

\subsection{Field Sampling and Biomass Measurements. Different} liana species were destructively sampled for the mixed species allometric equations from April to June 2012. Field sampling occurred in the rainy season during which leaf biomass was maximum [21]. To ensure that lianas sampled represented variation in microhabitats within the national park, lianas were sampled from slopes, valleys, and flatlands in each forest type. Sampling was conducted in such a way that there was even species representation from each forest type as much as possible. Lianas were harvested for biomass determination after measuring their diameter (at $1.3 \mathrm{~m}$ from the rooting base). In addition, the length of each harvested liana individual was measured. A total number of 60 liana individuals (30 each from the primary and secondary forests) were harvested (Table 1). The characteristics of the lianas harvested are indicated in Table 2. Lianas with clonal stems were rare in the study area and were not included in the study. Liana leaves were separated from stems, and both were sundried for 3 weeks and 2 months, respectively, for dry weight determination.

2.3. Data Analyses. Data exploration and preliminary model fitting were carried out to get models that best fit the data. Various models were initially developed using the original untransformed data, but only those that met regression assumptions (homogeneity of variance, linearity, normality, and nonautocorrelation) and had high goodness of fit were retained. Subsequently, a series of data transformation was carried out to find out whether better models could be developed from the transformation of data. Logarithmic transformation $\left(\log _{10}\right)$ and weighting of the independent variables (diameter and length) and the dependent variable (biomass) were found to be the best transformations which produced models that did not violate regression assumptions and at the same time had high goodness of fit. Homogeneity of variance and linearity of data were checked from residual plots whereas autocorrelation and normality were checked with Durbin-Watson statistics and probability plot, respectively.

Though logarithmic transformation is reported to increase the statistical validity of regression analysis by homogenising variance, it introduces a slight downward bias when data are back-transformed to arithmetic units [25]. To account for the bias, the back-transformed results from logarithmic unit are usually multiplied by a correction factor. Consequently, a correction factor (CF) was calculated for all logarithmic equations. The CF is given by the following equation [26]:

$$
\mathrm{CF}=\exp ^{\left((\mathrm{SEE} * 2.303)^{2} / 2\right)},
$$

where SEE is the standard error of the estimate.
TABLE 1: Number of individuals of liana species in the primary and secondary forests used for the allometric equations.

\begin{tabular}{lccc}
\hline \multirow{2}{*}{ Species } & \multicolumn{3}{c}{ Number of individuals } \\
& Primary forest & Secondary forest & Total \\
\hline Agelaea macrophylla & 2 & 2 & 4 \\
Artabotrys oblongus & 2 & 4 & 6 \\
Cnestis palala & 2 & 0 & 2 \\
Coptosapelta parviflora & 2 & 2 & 4 \\
Cyathostemma hookeri & 3 & 2 & 5 \\
Dalbergia rostrata & 1 & 4 & 5 \\
Gnetum latifolium & 3 & 2 & 5 \\
Rourea rugosa & 1 & 1 & 2 \\
Salacia sp. & 1 & 2 & 3 \\
Spatholobus ferrugineus & 2 & 2 & 4 \\
Strychnos curtisii & 3 & 0 & 3 \\
Strychnos ignatii & 2 & 1 & 3 \\
Tetracera macrophylla & 2 & 4 & 6 \\
Willughbeia sp. & 2 & 2 & 4 \\
Willughbeia angustifolia & 2 & 2 & 4 \\
\hline
\end{tabular}

TABLE 2: Summary of allometric properties of liana individuals used in the study.

\begin{tabular}{lccc}
\hline Parameter & Minimum & Maximum & Mean \\
\hline Diameter $(\mathrm{cm})$ & 1.30 & 14.20 & 5.39 \\
Length $(\mathrm{m})$ & 4.00 & 26.20 & 9.40 \\
Stem biomass $(\mathrm{kg})$ & 2.61 & 23.10 & 9.26 \\
Total above-ground biomass $(\mathrm{kg})$ & 3.03 & 26.70 & 10.78 \\
\hline
\end{tabular}

Due to the low abundance of lianas in the forests only mixed allometric equations were developed. Equations were developed using liana diameter, [diameter ${ }^{2}$, length, or a combination of them as estimate parameters.

Comparison of models was done using coefficient of determination $\left(R^{2}\right)$ and Furnival's index (FI). Models with the same response (dependent) variable were compared using $R^{2}$. For models with different dependent variables using $R^{2}$ to compare them could produce false results [27]. Consequently, Furnival's index [28] which is able to compare models of different dependent variables or weights was used to compare the logarithmic and nonlogarithmic models. The index is calculated as follows:

$$
\mathrm{FI}=\frac{1}{\left[f^{\prime}(Y)\right]} \sqrt{\mathrm{MSE}}
$$

where $f^{\prime}(Y)$ is the derivative of the dependent variable with respect to biomass, MSE is the mean square error of the fitted equation, and the square bracket ([ ]) is the geometric mean.

Regression analyses were conducted to determine the relationships between liana biomass and the various independent variables (diameter, length, and their combinations) for both untransformed and transformed data. Analysis of covariance (ANCOVA) was carried out to examine the possible effect of forest type on the various regression models. 
TABLE 3: Six previously published allometric equations (total aboveground liana biomass) used in comparing the current allometric equation. All the equations are based on the model form: total aboveground biomass $=\exp [c+\alpha \ln ($ diameter $)]$.

\begin{tabular}{lcc}
\hline Equation & $c$ & $\alpha$ \\
\hline Gehring et al. [21] & -1.547 & 2.640 \\
Gerwing and Farias [20] & 0.147 & 2.184 \\
Putz [29] & 0.036 & 1.806 \\
Hozumi et al. ${ }^{*}$ [22] & -1.347 & 2.391 \\
Beekman [30] & -1.459 & 2.566 \\
Schnitzer et al. [3] & -1.484 & 2.657 \\
\hline
\end{tabular}

* Based on a data set collected from Cambodia, Southeast Asia.

Forest type was used as the main factor whereas the various independent variables were used as covariables.

A current allometric equation for total above-ground biomass which was deemed as the best model based on Furnival's index of fit was compared with six previously published total above-ground biomass allometric equations of lianas (Table 3). Five of the equations were constructed from diameter-biomass data of lianas taken from individual studies. Three of the studies, namely, Gerwing and Farias [20], Gehring et al. [21], and Putz [29], contained published allometric biomass regression equations, but new versions of these equations were developed from their data sets by Schnitzer et al. [3]. Two of the studies [22, 30], on the other hand, did not have allometric equations but contained the diameter-biomass data which were used to construct allometric equations by Schnitzer et al. [3]. The sixth allometric equation [3] was constructed from combined data sets of all the above five studies (424 liana individuals). The equations were applied to a data set taken from the same forest (Penang National Park). The data was taken from 78 liana individuals comprising 27 species (diameter ranged from 1.4 to $14 \mathrm{~cm}$ ). Paired $t$-test was run to determine significant differences among total above-ground biomass values determined by each of the six previous equations and the current equation.

Regression analyses and $t$-test were conducted with the GenStat software (VSN International Ltd., Hemel Hempstead, UK) whereas ANCOVA was run with XLSTAT 2012.2 version (Addinsoft SARL, Paris, France). All analyses were conducted at a significance level of $5 \%$.

\section{Results and Discussion}

A total of seven different models each were developed for stem and total above-ground biomass of liana species (Tables 4 and 5). These could be categorised into three types of models: models fitted on the original arithmetic scale (models 1-3 and 8-10), weighted models fitted on the original arithmetic scale (models 4-5 and 11-12), and models fitted on logarithmic transformed data (models 6-7 and 1314). There was a significant linear relationship between the independent variables (diameter, length, [diameter $]^{2}$, and/or their combinations) and the dependent variables (stem and total above-ground biomass) in the allometric equations (Figures 2, 3, 4, 5, and 6).

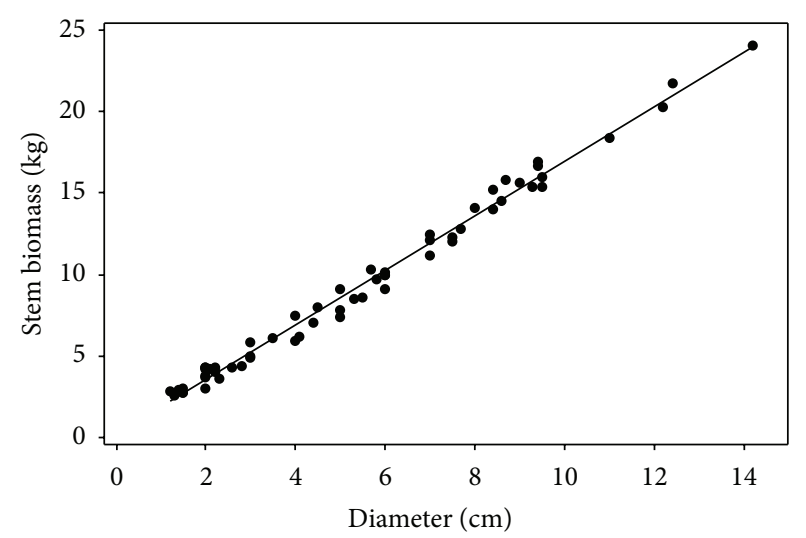

FIGURE 2: Liana allometric relationship between stem diameter and stem biomass of lianas.

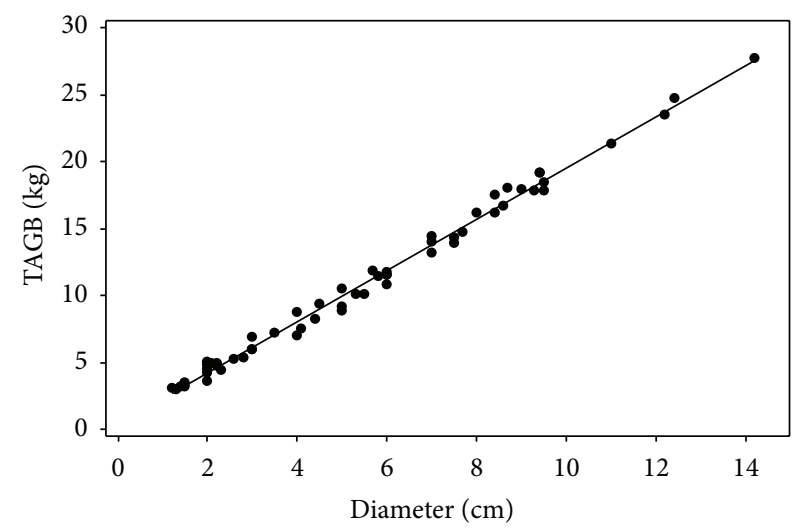

FIgURE 3: Liana allometric relationship between stem diameter and total above-ground biomass (TAGB) of lianas.

Generally, the models developed in this study exhibited high coefficients of determination $\left(R^{2} \geq 86 \%\right)$. Diameter is the commonest predictor in most biomass allometric equations [31] although length is also used in some studies (e.g. $[12,32])$. There were relatively higher coefficients of determination for the nontransformed allometric equations that used diameter as liana biomass predictor $\left(R^{2}=98.9\right.$ and $99.2 \%$ for stem and total biomass equations resp.) than those which used liana length as the predictor of liana biomass $\left(R^{2}=89.6\right.$ and $\left.90 \%\right)$. This indicates that liana diameter was a better predictor of liana biomass than liana length. Addition of liana length as a second estimator to liana allometric equations was found to improve upon goodness of fit of allometric equations of lianas in a study conducted in the Amazonian forest [21]. However, a different pattern was observed in this study, whereby there was no significant contribution of using length as a second estimator of both stem and total biomass models ( $P=0.066$ and 0.057 , resp.). Gehring et al. [21] used a much higher sample size $(n=439$ individuals) which could have affected the influence of liana length on the allometric equations developed in that study. Although the weighted form of liana diameter (diameter ${ }^{2}$ ) was a significant estimator of liana biomass, it yielded a 
TABLE 4: Allometric equations of mixed species for estimating liana stem biomass (kg).

\begin{tabular}{|c|c|c|c|c|c|c|}
\hline$\#$ & Equation & $c( \pm \mathrm{SE})$ & $\alpha( \pm \mathrm{SE})$ & $\beta( \pm$ SE $)$ & $R^{2}$ (adjusted) & FI \\
\hline 1 & Stem biomass $=c+\alpha D$ & $0.154 \pm 0.078$ & $1.731 \pm 0.028$ & - & 0.989 & 0.58 \\
\hline 2 & Stem biomass $=c+\alpha L$ & $2.55 \pm 0.189$ & $0.416 \pm 0.010$ & - & 0.896 & 1.70 \\
\hline 3 & Stem biomass $=c+\alpha D+\beta L$ & $0.474 \pm 0.258$ & $0.452 \pm 0.037$ & $0.394 \pm 0.010$ & 0.976 & 0.84 \\
\hline 4 & $(\text { Stem biomass })^{0.9}=c+\alpha D$ & $0.782 \pm 0.098$ & $1.210 \pm 0.015$ & - & 0.990 & 0.53 \\
\hline 5 & Stem biomass $=c+\alpha D^{2}$ & $0.144 \pm 0.089$ & $0.349 \pm 0.005$ & - & 0.861 & 2.63 \\
\hline 6 & $\log _{10}($ stem biomass $)=c+\alpha\left(\log _{10} D\right)$ & $0.396 \pm 0.0033$ & $1.086 \pm 0.042$ & - & 0.981 & 0.18 \\
\hline 7 & $\log _{10}($ stem biomass $)=c+\alpha\left(\log _{10} D\right)+\beta\left(\log _{10} L\right)$ & $0.165 \pm 0.002$ & $0.432 \pm 0.063$ & $0.431 \pm 0.062$ & 0.954 & 0.47 \\
\hline
\end{tabular}

\#: equation number; $D$ : liana diameter; $L$ : liana length.

TABLE 5: Allometric equations of mixed species for estimating total above-ground biomass (kg) of lianas.

\begin{tabular}{|c|c|c|c|c|c|c|}
\hline$\#$ & Equation & $c( \pm \mathrm{SE})$ & $\alpha( \pm \mathrm{SE})$ & $\beta( \pm \mathrm{SE})$ & $R^{2}$ (adjusted) & FI \\
\hline 8 & Total biomass $=c+\alpha D$ & $0.262 \pm 0.181$ & $1.934 \pm 0.029$ & - & 0.992 & 0.58 \\
\hline 9 & Total biomass $=c+\alpha L$ & $3.120 \pm 0.413$ & $0.476 \pm 0.021$ & - & 0.900 & 1.92 \\
\hline 10 & Total biomass $=c+\alpha D+\beta L$ & $0.768 \pm 0.280$ & $0.511 \pm 0.040$ & $0.450 \pm 0.010$ & 0.987 & 0.89 \\
\hline 11 & $(\text { Total biomass })^{0.9}=c+\alpha D$ & $1.041 \pm 0.096$ & $1.354 \pm 0.015$ & - & 0.993 & 0.53 \\
\hline 12 & Total biomass $=c+\alpha D^{2}$ & $0.194 \pm 0.041$ & $0.405 \pm 0.007$ & - & 0.904 & 2.41 \\
\hline 13 & $\log _{10}($ total biomass $)=c+\alpha\left(\log _{10} D\right)$ & $0.490 \pm 0.021$ & $1.090 \pm 0.027$ & - & 0.986 & 0.22 \\
\hline 14 & $\log _{10}($ total biomass $)=c+\alpha\left(\log _{10} D\right)+\beta\left(\log _{10} L\right)$ & $0.275 \pm 0.021$ & $0.470 \pm 0.066$ & $0.452 \pm 0.044$ & 0.960 & 0.49 \\
\hline
\end{tabular}

\#: equation number; $D$ : liana diameter; $L$ : liana length.

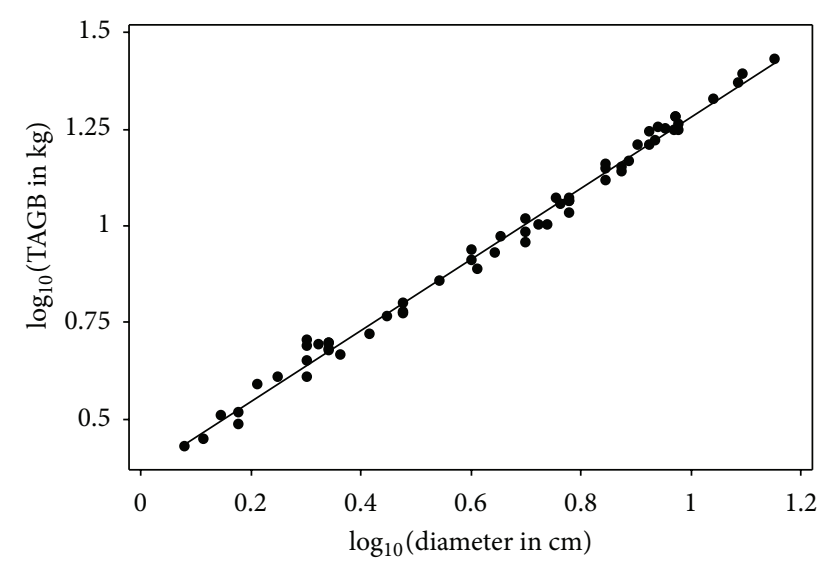

FIGURE 4: Liana allometric relationship between $\log _{10}$ stem diameter and $\log _{10}$ total above-ground biomass (TAGB) of lianas.

much lower coefficient of determination (models 5 and 12) compared to its unweighted diameter equations (models 1 and 8). Addition of liana length as a second predictor in the logarithmic models (models 7 and 14) did not improve goodness of fit significantly $(P=0.318$ and 0.423 for stem and total biomass, resp.) just as observed in the raw data models.

Based on Furnival's index (FI) of fit, the logarithmic transformed allometric equations performed better than the other models in both stem and total above-ground models. Whereas the FI values for all the logarithmic transformed models were below 0.5 , those of the other models were above 0.5. Considering the fact that measuring liana length on the field is impossible without harvesting them, it is practically not feasible to use allometric equations incorporating liana

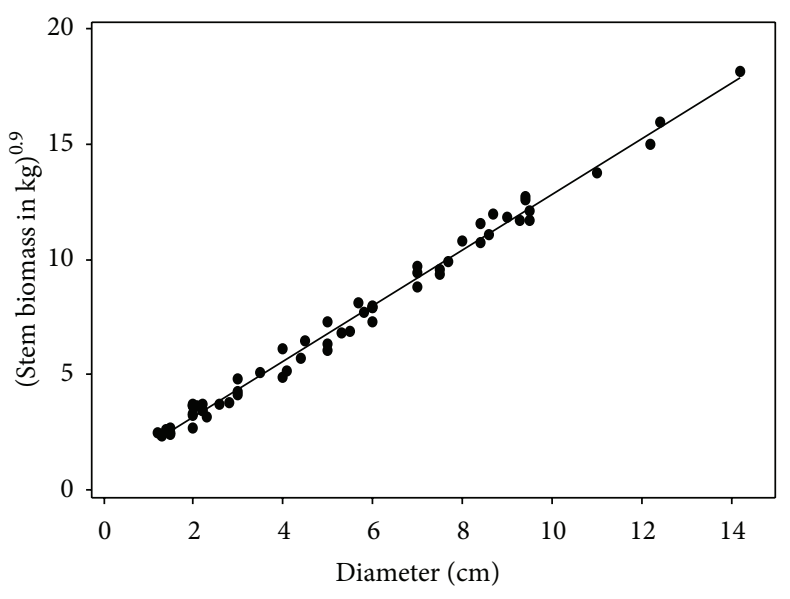

FIgURE 5: Liana allometric relationship between stem diameter and (stem biomass in $\mathrm{kg})^{0.9}$ of lianas.

length. Additionally, the inclusion of length may introduce propagated variance and recirculation of estimation errors at each subsequent prediction period (cf. [33]). For these reasons, the allometric equations which used only liana diameter as the predictor are recommended for use in liana biomass determination. Out of the equations that used only diameter as the independent variable, models 6 and 13 could be selected as the best models for determining liana stem and total above-ground biomass as they had the lowest FI values ( 0.18 and 0.22 , resp.) in the study. The overall superiority of the logarithmic transformed models to the other models lends support to the finding that log transformation provides better fit than untransformed data in most cases [33]. 


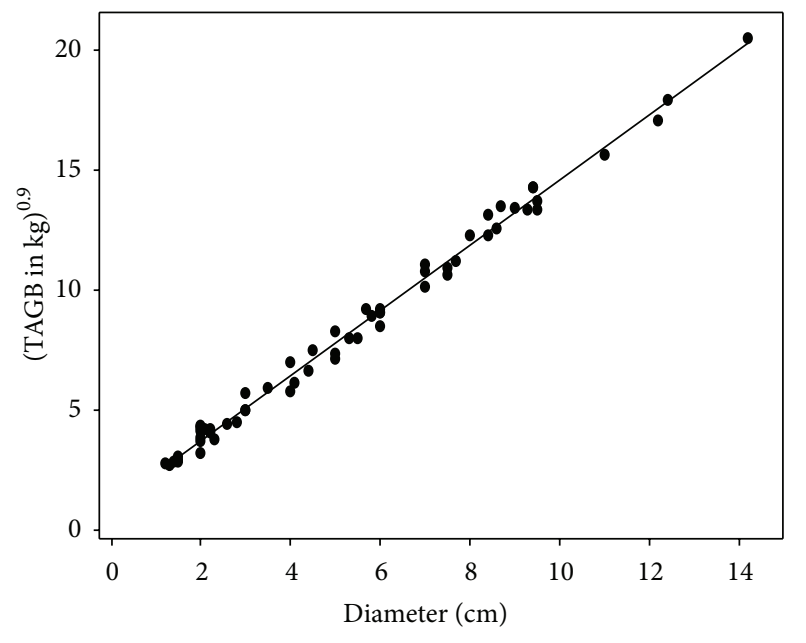

FIGURE 6: Liana allometric relationship between stem diameter and (TAGB in $\mathrm{kg})^{0.9}$ of lianas (TAGB: total above-ground biomass).

TABLE 6: Correction factor (CF) of logarithmic models for stem and total above-ground biomass of lianas.

\begin{tabular}{lcr}
\hline \multirow{2}{*}{ Model } & \multicolumn{2}{c}{ CF } \\
& Stem & Total \\
\hline $\log _{10}$ (biomass) $=c+\alpha\left(\log _{10} D\right)$ & 1.005 & 1.002 \\
$\log _{10}$ (biomass) $=c+\alpha\left(\log _{10} D\right)+\beta\left(\log _{10} L\right)$ & 1.011 & 1.011 \\
\hline
\end{tabular}

Due to the systematic bias introduced by log transformation of data, correction factor is normally calculated for logarithmic transformed allometric equations so as to account for the bias. The correction factor values determined for the various log-transformed allometric equations (Table 6) were generally low $(0.2-1.1 \%)$ indicating that the downward bias of the equations was marginal.

There was no significant effect of forest type on the allometric equations developed in the study (ANCOVA; $P>$ 0.05 ) indicating that the equations could be used in both primary and secondary forests. This finding is supported by Gehring et al. [21] who did not observe significant change in the goodness of fit of liana allometric equations when forest age was factored in.

Comparison of the best total above-ground biomass model with previously published equations (Table 3) indicated that the current equation differed considerably from them. All the previous allometric equations overestimated total above-ground biomass when they were applied to a data set taken from the same forest (Penang National Park, Malaysia) (Figure 7). The overestimation of total aboveground biomass of lianas ranged from 29 to $74.5 \%$. The mean total above-ground biomass per liana species estimated by five of the previous equations differed significantly (Table 7; $P<0.05)$ from that of the current study. Interestingly, the allometric equation developed from a data set from Southeast Asia $[3,22]$ provided the lowest overestimation, and its mean total above-ground biomass did not differ significantly $(P=0.079)$ from that of the current allometric equation. This indicates that allometric equations from the

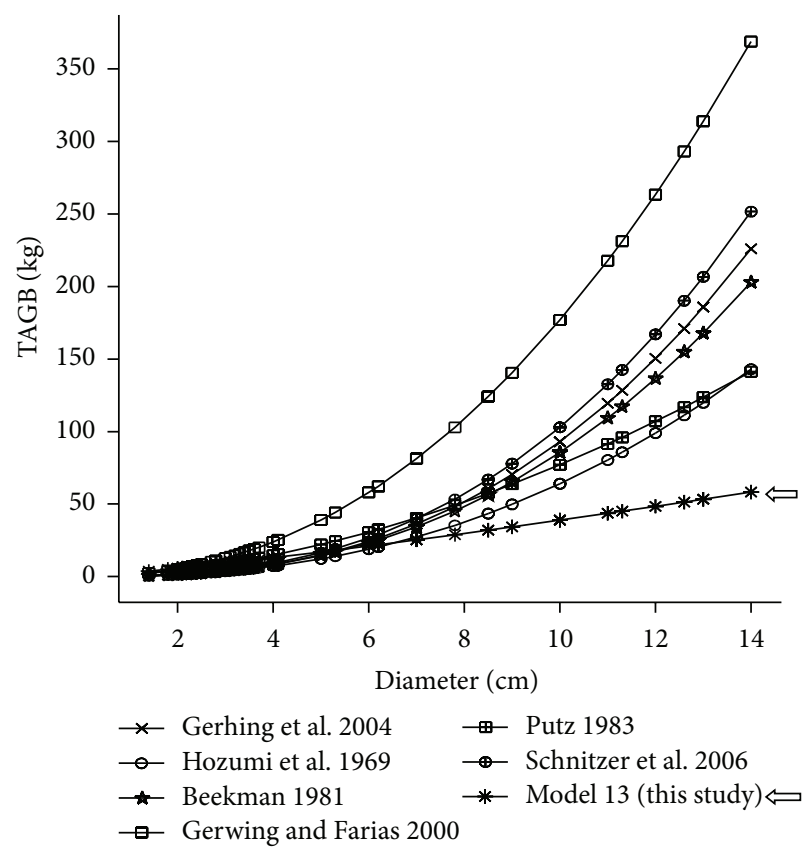

FIGURE 7: Comparison of model 13 with previously reported models for determination of liana total above-ground biomass (TAGB) in tropical forests.

same region may be more similar in their estimation of biomass. Among the previous equations was one that was developed from data sets of five different sites from four countries (Table 3). Consequently, this equation is considered a more general equation which could be more useful in other forest ecosystems in the tropics. However, this equation even overestimated total above-ground biomass of lianas by as much as $44 \%$. The underestimation of total above-ground biomass of lianas by the current equation may be due to low liana wood density in the Penang National Park from which it was developed. Equations developed from low wood density forests are likely to underestimate plant biomass whereas equations developed from high wood density forests may overestimate plant biomass in some forests [12, 32]. The comparison of the previous equations to the current one has revealed the need for site specific models to be encouraged for accurate determination of liana biomass in tropical forests. However, where site specific allometric equations are not available, care must be taken in choosing allometric equations for forests. In that case, equations within the same region or continent should be explored first.

\section{Conclusion}

Some allometric relationships were developed for liana stem and total above-ground biomass using liana diameter, length, diameter squared, and a combination of them as predictors. Three types of liana allometric equations were developed: (1) models fitted to logarithmic transformed data, (2) weighted models fitted to data (both dependent and independent data) on original arithmetic scale, and (3) models fitted to data 
TABLE 7: Comparison of mean estimated total above-ground biomass (per species) between model 13 and six previously published allometric equations (see Table 3 ) with $t$-test. The value in parenthesis represents the mean biomass for the current equation whereas those outside the parenthesis represent the means of the previous equations.

\begin{tabular}{lcc}
\hline Pair & Mean & $P$ value \\
\hline $\begin{array}{l}\text { Model 13 versus Gehring et al. } \\
\text { [21] }\end{array}$ & $126.64(62.40)$ & 0.023 \\
$\begin{array}{l}\text { Model 13 versus Gerwing and } \\
\text { Farias [20] }\end{array}$ & $242.30(62.40)$ & $<0.001$ \\
Model 13 versus Putz [29] & $108.68(62.40)$ & 0.019 \\
$\begin{array}{l}\text { Model 13 versus Hozumi et al. } \\
\text { [22] }\end{array}$ & $87.07(62.40)$ & 0.079 \\
$\begin{array}{l}\text { Model 13 versus Beekman [30] } \\
\text { Model 13 versus Schnitzer et al. }\end{array}$ & $116.48(62.40)$ & 0.034 \\
{$[3]$} & $140.3(62.40)$ & 0.013 \\
\hline
\end{tabular}

on original arithmetic scale. Liana diameter was a better estimator of liana stem and total above-ground biomass compared to liana length. Hence, the models that used only liana diameter as the parameter estimate are recommended for use. Liana allometric equations developed in the study could be used in both primary and secondary forests as they were not affected by forest type. A comparison of the best total above-ground allometric equation developed in this study (model 13) with previously published models indicated that the previous equations overestimated total above-ground biomass of lianas by at least $29 \%$.

\section{Conflict of Interests}

The authors do not have any direct financial relation or whatsoever with the content of their paper that might lead to a conflict of interests for any of the authors. Consequently, they declare no conflict of interests.

\section{Acknowledgments}

This study was supported by TWAS-USM Postgraduate Fellowship and Research University (RU) Grant (1001/PBIOLOGI/815086). The authors are grateful to Mr. Abu Husin of the Forest Research Institute, Malaysia, and Mr. Ntim Gyakari of the Forestry Commission of Ghana for their assistance in plant identification. They finally thank Mr. S. M. Edzham of the School of Biological Sciences, USM, Malaysia, for his immense assistance in the field.

\section{References}

[1] S. A. Schnitzer and F. Bongers, "The ecology of lianas and their role in forests," Trends in Ecology and Evolution, vol. 17, no. 5, pp. 223-230, 2002.

[2] P. Addo-Fordjour, A. K. Anning, E. A. Atakora, and P. S. Agyei, "Diversity and distribution of climbing plants in a semi-deciduous rain forest, KNUST Botanic Garden, Ghana," International Journal of Botany, vol. 4, no. 2, pp. 186-195, 2008.
[3] S. A. Schnitzer, S. J. DeWalt, and J. Chave, "Censusing and measuring lianas: a quantitative comparison of the common methods," Biotropica, vol. 38, no. 5, pp. 581-591, 2006.

[4] F. Bongers, M. P. E. Parren, M. D. Swaine, and D. Traoré, "Forest climbing plants of West Africa: introduction," in Forest Climbing Plants of West Africa: Diversity, Ecology and Management, F. Bongers, M. P. E. Parren, and D. Traoré, Eds., pp. 5-18, CAB International, Oxfordshire, UK, 2005.

[5] K. Lertpanich and W. Y. Brockelman, "Lianas and environmental factors in the Mo Singto Biodiversity Research plot, Khao Yai National Park, Thailand," Natural History Journal of Chulalongkorn University, vol. 3, pp. 7-17, 2003.

[6] Y. Tang, R. L. Kitching, and M. Cao, "Lianas as structural parasites: a re-evaluation," Chinese Science Bulletin, vol. 57, no. 4, pp. 307-312, 2012.

[7] D. R. Pérez-Salicrup, "Effect of liana cutting on tree regeneration in a liana forest in Amazonian Bolivia," Ecology, vol. 82, no. 2, pp. 389-396, 2001.

[8] D. R. Pérez-Salicrup and M. G. Barker, "Effect of liana cutting on water potential and growth of adult Senna multijuga (Caesalpinioideae) trees in a Bolivian tropical forest," Oecologia, vol. 124, no. 4, pp. 469-475, 2000.

[9] S. A. Schnitzer, J. W. Dalling, and W. P. Carson, “The impact of lianas on tree regeneration in tropical forest canopy gaps: evidence for an alternative pathway of gap-phase regeneration," Journal of Ecology, vol. 88, no. 4, pp. 655-666, 2000.

[10] W. F. Laurance, "Reflections on the tropical deforestation crisis," Biological Conservation, vol. 91, no. 2-3, pp. 109-117, 1999.

[11] International Tropical Timber Organization (ITTO), ITTO Guidelines For the Restoration, Management and Rehabilitation of Degraded and Secondary Tropical Forests, ITTO Policy Development Series No. 13, International Tropical Timber Organization (ITTO), Yokohama, Japan, 2002.

[12] T. Kenzo, R. Furutani, D. Hattori et al., "Allometric equations for accurate estimation of above-ground biomass in loggedover tropical rainforests in Sarawak, Malaysia," Journal of Forest Research, vol. 14, no. 6, pp. 365-372, 2009.

[13] J. Chave, D. Coomes, S. Jansen, S. L. Lewis, N. G. Swenson, and A. E. Zanne, "Towards a worldwide wood economics spectrum," Ecology Letters, vol. 12, no. 4, pp. 351-366, 2009.

[14] D. Tilman, P. B. Reich, J. Knops, D. Wedin, T. Mielke, and C. Lehman, "Diversity and productivity in a long-term grassland experiment," Science, vol. 294, no. 5543, pp. 843-845, 2001.

[15] D. B. MacKay, P. M. Wehi, and B. D. Clarkson, "Evaluating restoration success in urban forest plantings in Hamilton, New Zealand," Urban Habitats, vol. 6, no. 1, 2011.

[16] Q. M. Ketterings, R. Coe, M. Van Noordwijk, Y. Ambagau', and C. A. Palm, "Reducing uncertainty in the use of allometric biomass equations for predicting above-ground tree biomass in mixed secondary forests," Forest Ecology and Management, vol. 146, no. 1-3, pp. 199-209, 2001.

[17] S. A. Schnitzer and F. Bongers, "Increasing liana abundance and biomass in tropical forests: emerging patterns and putative mechanisms," Ecology Letters, vol. 14, no. 4, pp. 397-406, 2011.

[18] J. R. Moore, "Allometric equations to predict the total aboveground biomass of radiata pine trees," Annals of Forest Science, vol. 67 , no. 8, p. 806, 2010.

[19] E. E. Hegarty and G. Caballé, "Distribution and abundance in forest communities," in The Biology of Vines, F. E. Putz and H. A. Mooney, Eds., pp. 313-335, Cambridge University Press, Cambridge, UK, 1991. 
[20] J. J. Gerwing and D. L. Farias, "Integrating liana abundance and forest stature into an estimate of total aboveground biomass for an eastern Amazonian forest," Journal of Tropical Ecology, vol. 16, no. 3, pp. 327-335, 2000.

[21] C. Gehring, S. Park, and M. Denich, "Liana allometric biomass equations for Amazonian primary and secondary forest," Forest Ecology and Management, vol. 195, no. 1-2, pp. 69-83, 2004.

[22] K. Hozumi, K. Yoda, S. Kokawa, and T. Kira, "Production ecology of tropical rain forests in south-western Cambodia. I. Plant biomass," Oecologia, vol. 145, pp. 87-99, 1969.

[23] H. C. Wern and C. N. Weng, "The Potentials, threats and challenges in sustainable development of Penang National Park," Malaysian Journal of Environmental Management, vol. 11, pp. 95-109, 2010.

[24] P. Addo-Fordjour, Z. B. Rahmad, and A. M. S. Shahrul, "Effects of human disturbance on liana community diversity and structure in a tropical rainforest, Malaysia: implication for conservation," Journal of Plant Ecology, vol. 5, no. 4, pp. 391-399, 2012.

[25] G. L. Baskerville, "Use of Logarithmic regression in the estimation of plant biomass," Canadian Journal of Forest Research, vol. 2, no. 1, pp. 49-53, 1972.

[26] D. G. Sprugel, "Correcting for bias in log-transformed allometric equations," Ecology, vol. 64, no. 1, pp. 209-210, 1983.

[27] B. R. Parresol, "Assessing tree and stand biomass: a review with examples and critical comparisons," Forest Science, vol. 45, no. 4, pp. 573-593, 1999.

[28] G. M. Furnival, "An index for comparing equations used in constructing volume tables," Forest Science, vol. 7, pp. 337-341, 1961.

[29] F. E. Putz, "Liana biomass and leaf area of a "tierra firme" forest in the Rio Negro Basin, Venezuela," Biotropica, vol. 15, no. 3, pp. 185-189, 1983.

[30] F. Beekman, Structural and Dynamic Aspects of the Occurrence and Development of Lianes in the Tropical Rain Forest, Department of Forestry, Agricultural University, Wageningen, The Netherlands, 1981.

[31] S. T. Gower, C. J. Kucharik, and J. M. Norman, "Direct and indirect estimation of leaf area index, f(APAR), and net primary production of terrestrial ecosystems," Remote Sensing of Environment, vol. 70, no. 1, pp. 29-51, 1999.

[32] T. Kenzo, T. Ichie, D. Hattori et al., "Development of allometric relationships for accurate estimation of above- and belowground biomass in tropical secondary forests in Sarawak, Malaysia," Journal of Tropical Ecology, vol. 25, no. 4, pp. 371-386, 2009.

[33] C. Wang, "Biomass allometric equations for 10 co-occurring tree species in Chinese temperate forests," Forest Ecology and Management, vol. 222, no. 1-3, pp. 9-16, 2006. 

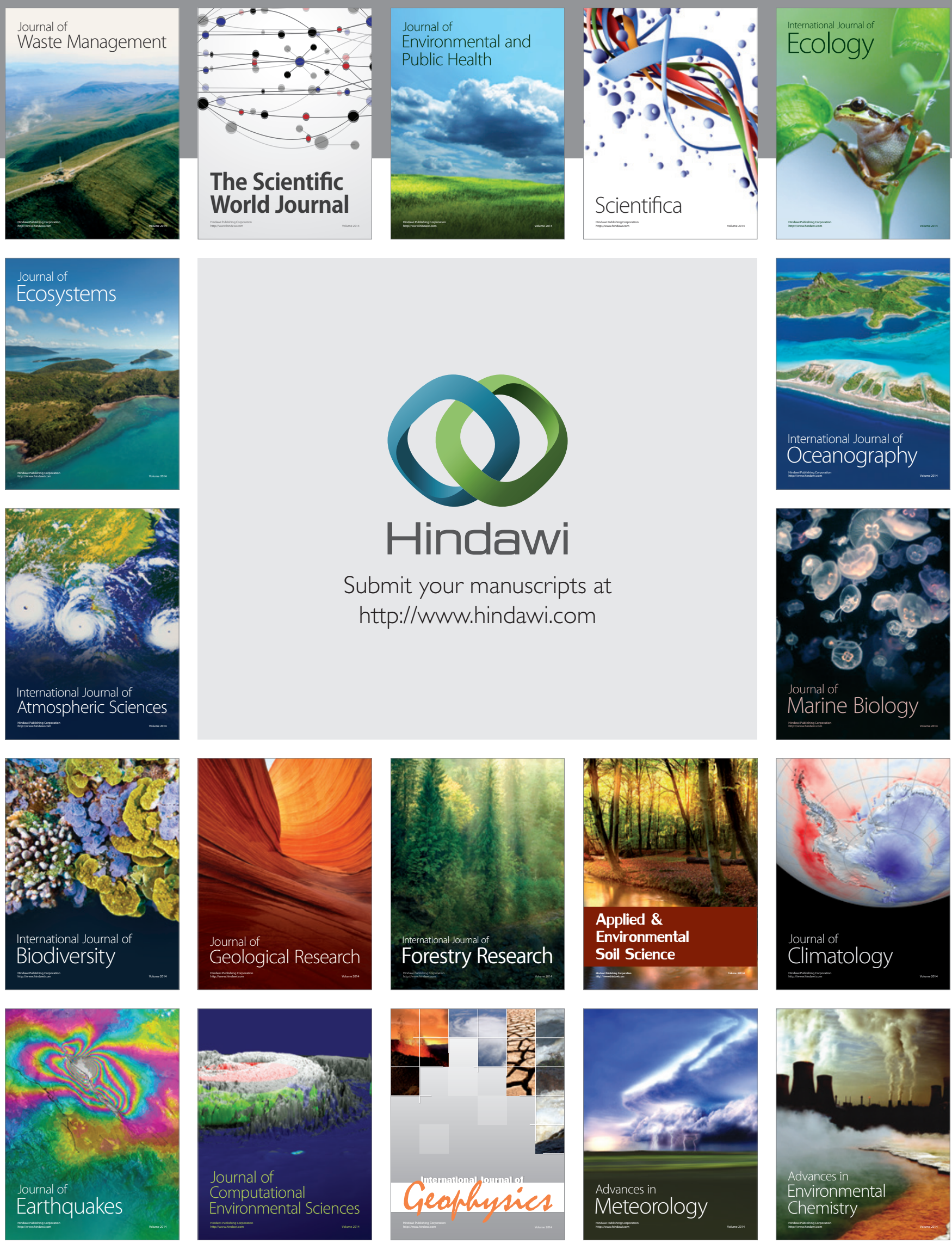